\title{
Os afazeres de Babel
}

\author{
José Quintão de Oliveira \\ Universidade Federal de Minas Gerais
}

\section{Abstract}

We live in a time that might be called a time of translation. Everywhere, we need to read or to listen to utterances that were originally written or spoken in languages that are strange to us. So, we do not need a theoretical approach to conclude that it is possible to translate a text from one language to a different one. But, is this real? Especially, is this real when we talk about Literature? Is possible to translate a poem? Beginning with Cicero in Ancient Rome, we trace a rout through Saint Jerome, Ortega y Gasset and other thinkers to discuss the answers to these questions. This short essay is just a first approach which more than supplying answers, seeks for a debate on the important questions related to this subject. It has only one conclusion: two thousand years of reflections on the problem of translation has not been sufficient to solve it. 
"Non solum fateor, sed libera uoce profiteor me in interpretatione Graecorum absque scripturis sanctis, ubi et uerborum ordo mysteriam est, non uerbum e uerbo sed sensum exprimere de sensu."

(Eusebius Hieronymus)

$\mathrm{E}$ ste pequeno ensaio propõe-se a discutir alguns dos problemas ligados à tradução interlingual das obras literárias. Partindo de uma parábola sobre o trabalho do tradutor, tentaremos localizar as raízes do problema já a partir da origem etimológica dos termos relacionados aos afazeres da tradução.

Dos diversos tipos de tradução à "impossibilidade" de se traduzir poesia, discutiremos algumas das posições teóricas presentes no debate sobre a transposição da obra literária.

Da Antiguidade Clássica aos nossos dias, passando por grandes pensadores da cultura ocidental, a tradução representa um problema desafiador e provocativo sobre o qual muita reflexão já se acumulou, mas que demanda ainda muito debate, pois, quanto mais se traduz e se reflete sobre o tema, mais precárias tornam-se as certezas com que operamos.

Cícero é a primeira referência teórica de que dispomos sobre o assunto. Tomando-o como ponto inicial da nossa reflexão, discutiremos a tradução e suas implicações, procurando entender os dilemas que enfrenta o tradutor na sua rotina de trabalho.

\section{OS AFAZERES DE BABEL}

Através do necrológio de Pierre Menard, datado de Nimes, França, 1939, tomamos conhecimento da gigantesca empresa a que se propôs esse escritor: escrever um novo Quixote. "No queria componer outro Quijote - lo qual es fácil - sino el Quijote"1 (BORGES, 1989, p. 446), diz-nos seu necrologista. "Su admirable ambición era producir unas páginas que coincidieran - palabra por palabra y línea por línea - com las de Miguel de Cervantes." (BORGES, 1989, p. 446). Disse 
sobre seu projeto o próprio Pierre Menard: "Mi propósito es meramente assombroso", ${ }^{3}$ em carta expedida em 30 de setembro de 1934, de Bayonne, e destinada ao seu futuro necrologista. "Mi empresa no es difícil, essencialmente, me bastaria ser inmortal para llevarla a cabo" ${ }^{4}$ - conclui (BORGES, 1989, p. 447).

Fala o necrologista:

El método inicial que imaginó era relativamente sencillo. Conocer bien el español, recuperar la fe católica, guerrear contra los moros e contra el turco, olvidar la historia de Europa entre los años 1602 y de 1918, ser Miguel de Cervantes. ${ }^{5}$ (BORGES, 1989, p 447)

Menard teria estudado esse método - tendo chegado a um manejo bastante fiel do espanhol do século dezessete - mas descartou-o, por considerá-lo excessivamente fácil. Pouco restou do seu trabalho: os capítulos nono e trigésimo-oitavo da primeira parte e um fragmento do capítulo vinte e dois do Quijote. Isso é tudo o que sobrou do trabalho de uma vida inteira.

Pierre Menard, todos sabem, é um personagem de ficção, criação do escritor argentino Jorge Luís Borges; está no conto "Pierre Menard, Autor del Quijote", do livro Ficciones. Mas seu drama e seus impasses são mais do que reais para aqueles que se aventuram a traduzir obras literárias. É uma parábola sobre a tradução da prosa literária e da poesia. Não é o mesmo de Menard, o sonho de todo tradutor? Reescrever - em uma outra língua - uma obra literária, oferecendo-a íntegra e original aos leitores, separados do autor por diferenças culturais gigantescas e, às vezes, por séculos e séculos. Menard fracassou em sua empreitada. E ao tradutor, que destino está reservado em sua inglória tarefa?

Nossa razão cotidiana, o senso comum, nos diz, sem necessitar de se apoiar na teoria, que é possível traduzir de uma a outra língua. Crescemos lendo livros de autores do mundo inteiro, vendo filmes e programas de televisão traduzidos. Homens e mulheres dos mais distantes pontos da terra interagem diariamente, sem que a existência de milhares de diferentes línguas ${ }^{6}$ seja obstáculo a essa interação. 
Pode-se dizer que a tradução é parte da rotina do mundo moderno e que assim tem sido há longo tempo. É interessante perguntar-se sobre até onde essa constatação reflete a realidade.

O verbo traduzir origina-se do latim traducere, que significa 'conduzir, fazer passar, fazer desfilar, transferir, atravessar', etc. Assim, traduzir é conduzir, fazer passar de uma a outra língua. Convém acrescentar que esse verbo era usado pelos que falavam e escreviam em latim sempre para referir-se ao transporte de seres vivos. Para seres inanimados havia o verbo transferre, supino translatum, que deu origem ao verbo trasladar em português. Daí, "trasladar o corpo" que lemos nos jornais e ouvimos no rádio. De translatum, aliás, originase a palavra translatio, que deságua na palavra translation, que no inglês dos nossos dias significa tradução, donde, to translate - 'traduzir'.

O ensaísta Alberto Manguel conta uma deliciosa história e define com muita propriedade o ato da tradução:

Na alta Idade Média, tradução (translation, no original em inglês) significava a trasladação dos restos mortais de um santo de um lugar para outro. Às vezes, essas trasladações eram ilegais, quando os restos santificados eram roubados de uma cidade e levados para a maior glória de outro lugar. Foi assim que o corpo de São Marcos foi transferido de Constantinopla para Veneza, escondido sob um carregamento de carne de porco em que os guardas turcos dos portões de Constantinopla se recusaram a tocar. Levar embora algo precioso e tornar-se proprietário dele por qualquer meio possível: essa definição talvez sirva melhor para o ato de tradução literária. (MANGUEL, 2000, p. 134-5)

O lingüista e crítico literário russo Roman Jakobson (1969) fala de três tipos básicos de tradução. A tradução intralingual ou reformulação, que consiste na interpretação dos signos verbais através de outros signos verbais da mesma língua. Dessa forma, um poema pode ser reformulado ou traduzido em prosa poética, por exemplo. A tradução interlingual, em que um texto ou obra literária produzidos em uma língua de origem (LO) é vertido para uma língua terminal ou língua de chegada (LT), ou, em inglês, source language 
e target language, respectivamente. Outro tipo de tradução é a tradução intersemiótica, em que obras de arte originadas em meio de expressão são vertidas para outro meio. Assim, um poema pode ser traduzido em uma sinfonia ou em um filme; um romance se torna filme ou peça de teatro. Nossa época tem-se caracterizado como uma época da tradução interlingual, mas também vivemos, sem dúvida nenhuma, um período riquíssimo em traduções intersemióticas. Apenas a tradução interlingual será objeto deste texto, que tem como principal centro de atenção a tradução do texto poético entre diferentes línguas.

\section{AS ORIGENS DO PROBLEMA}

As primeiras reflexões sobre tradução de que temos notícia remontam a Cícero (106-43 a.C.), que traduziu do grego para o latim os Discursos de Ésquines e Demócrito sobre a chamada "questão da coroa" - obra desaparecida, que deu origem ao texto de que falaremos à frente - e também obras de Xenofonte e Platão. O orador do Fórum foi ainda tradutor de poesia helenística, tendo vertido ao latim o poema "Phaenomena" ("Os Fenômenos"), do poeta Arato de Solos. O que sobreviveu desse trabalho está reunido na Aratea. Em sua obra De optimo genere oratorum, que era originalmente introdução à tradução dos Discursos, Cícero distingue dois tipos básicos de tradução: "ut interpres" e "ut orator". Essa é a mais antiga reflexão sobre a arte de traduzir que se conhece na cultura ocidental e constitui um verdadeiro tratado sobre o assunto. Segundo esse autor, ele teria traduzido os Discursos de Ésquines e Demócrito não como mero tradutor ${ }^{7}$ ( ut interpres), mas como verdadeiro orador (ut orator) (CICERUS, 1934, p. 238).

Os discursos traduzidos por Cícero, segundo alguns estudiosos (São Jerônimo entre eles), são os mais importantes de Atenas produzidos pelos dois maiores e mais importantes oradores atenienses, um em oposição ao outro. Ao dizer que os traduziu ut orator, Cícero está dizendo que não se limitou a transcrever em latim 
o que originalmente estava escrito em grego, mas que os reconstruiu na nova língua, para assim recuperar na nova cultura o sentido original da obra traduzida.

São Jerônimo diz, como está na epígrafe deste ensaio: "Não só o admito, mas repito em voz alta com toda franqueza: ao traduzir os gregos - exceto nas Santas Escrituras, onde a ordem das palavras é também um mistério ${ }^{8}$ - não traduzo palavra por palavra, mas sentido por sentido." (SAN JERÓNIMO, 1994, p. 209). Diz ainda, na mesma epístola, citando o Horácio da "Ars Poetica": "nec uerbum uerbo curabis reddere fidus interpres"10 - não te preocupes em pôr palavra por palavra como fiel intérprete (SAN JERÓNIMO, 1994, p. 210). Algumas linhas à frente, o Santo cita o prólogo por ele mesmo escrito para a tradução que fizera ao latim da obra de Eusébio:

É difícil que aquele que segue as linhas traçadas por outro não se separe delas em algum ponto, é verdadeiramente difícil que o que foi bem dito em outra língua conserve a mesma beleza na tradução. Pode ocorrer que algo se expresse com a exatidão de uma única palavra, mas não disponho do termo adequado para traduzi-la, entretanto cuido de completar o sentido, cubro a duras penas com um largo rodeio o trajeto de um caminho breve. Acrescente-se a isto a sinuosidade dos hipérbatos, as diferenças de casos, as variedades de figuras, enfim, a idiossincrasia mesma da língua, que lhe é própria e, por assim dizer, parte de sua natureza ${ }^{11}$. (idem, ibidem)

Assim, o Santo tradutor da Bíblia, quase quinhentos anos depois de Cícero, guia-se pelos mesmos princípios que guiaram o orador romano, firmando desta maneira uma forma de traduzir que chega aos nossos dias como o procedimento que busca ser capaz de transpor de uma a outra cultura a obra literária.

Diz Roman Jakobson em seu ensaio, publicado pela primeira vez em inglês, na coletânea On Translation da Editora da Universidade de Harvard: “...não há comumente equivalência completa entre as unidades de código (palavras), ao passo que as mensagens podem servir como interpretações adequadas das unidades de código ou mensagens estrangeiras." (JAKOBSON, 1969, p. 65). 
Segundo ainda esse mesmo pensador, ao traduzir de uma língua para outra, substituímos mensagens por mensagens e não unidades de código (isto é, palavras) por unidades de código.

Ao orador do fórum romano e ao Santo de Stridon junta-se o formalista russo, definindo a tradução como ato recriador, ao reconhecer que a simples transposição de vocábulos de uma à outra língua não seria capaz de traduzir o conteúdo, isto é, o real sentido da obra de arte literária.

Alguém já deve ter dito que uma boa metáfora para o ato de traduzir é compará-lo a um naufrágio, em que o marinheiro/tradutor tem de trabalhar duramente para evitar que toda a carga vá a pique juntamente com a embarcação que afunda. Diferentemente de Robinson Crusoé, ele sabe que as ondas não carregarão suavemente o barco naufragado até a praia, garantindo-lhe suprimentos para uma vida inteira. Depois do duro trabalho, sentir-se-á feliz diante do pouco que conseguiu transportar à terra firme da língua de chegada.

\section{POÉTICA DA TRADUÇÃO}

Toda tradução exige dedicação, pesquisa e muito trabalho por parte do tradutor, mas as dificuldades oferecidas por uma tradução técnica são bem menores que aquelas apresentadas por uma tradução de uma obra literária, ${ }^{12}$ principalmente obras poéticas. Isso se dá porque, entre outros motivos, nas obras literárias a carga semântica é muito mais alta que nas obras técnicas. O texto técnico requereria uma leitura apenas parafrástica, ao passo que a poesia requer uma leitura polissêmica. A experiência cotidiana de todo leitor de mais de uma língua mostra que é perfeitamente factível ler um texto técnico traduzindo-o à língua de chegada simultaneamente. O já citado Roman Jakobson, em seu ensaio anteriormente referido, define tudo em poucas palavras: "... a poesia, por definição, é intraduzível. Só é possível a transposição criativa ..." (JAKOBSON, 1969, p. 72).

No prefácio para a edição em livro de um seminário realizado na Universidade das Canárias, o tradutor e teórico da tradução 
australiano, Anthony Pym (1993, p. 13) afirma que a discussão que ele propõe sobre tradução deve-se basear em duas idéias. "A primeira idéia", diz ele, "é que a tradução não pode ser pensada ou teorizada de forma autoritária". Assim, diz o autor: "Isso significa que quando ensino tradução e um estudante pergunta diretamente: 'como posso traduzir isso?', minha mais honesta resposta começa com um 'eu não sei'.” (PYM, 1993, p. 13). A segunda idéia "é um pouco mais complicada", declara Pym, "ela diz que tradução é levada a cabo em comunidades interculturais". Segundo Pym, o tradutor não pertence a uma cultura ou à outra, mas sim a "uma comunidade que cruza ao menos duas culturas". Assim, o tradutor conserva um pé em sua cultura nativa e pisa com o outro pé em outra cultura, numa posição que lhe permite produzir comunicação transcultural (PYM, 1993, p.14). Para esse autor, parece que o tradutor, mais que obras literárias, traduz culturas. Podemos, assim, resumir seu pensamento em duas palavras: 'humildade e respeito', que servem como a melhor máxima para aqueles que se propõem ao ofício da tradução. Do trabalho do tradutor, disse Ortega y Gasset que “...na organização intelectual não há tarefa mais humilde.” (1964, p. 434). Com ele parece concordar Anthony Pym.

Tomando aleatoriamente algumas palavras, por exemplo: edifício, morcego, sindicato, elas podem ser traduzidas para o inglês sem dificuldade por building, bat, union. Nenhum problema encontramos aí, para traduzi-las em um tratado de um catálogo de engenharia, um manual de botânica, ou numa reportagem sobre o movimento sindical. Traduzir-se building por edifício e vice-versa, não representa dificuldade. Mas building, em inglês, não é apenas 'edifício'. Esse substantivo contém também o verbo to build ('construir') e seu gerúndio (building), com a chamada forma ing, declinação verbal muito usada em inglês e inexistente em português, o que aproxima semanticamente o substantivo da ação, e que se perdeu na tradução. De morcego para bat ocorre outro tipo de perda. A aproximação fonética entre as palavras bat e rat ('rato', em inglês) perdeu-se na tradução, pois o mor- de morcego ('mur' no português 
do século treze e muris em latim, 'rato'; donde, morcego - rato cego) há muito não existe mais em nossa língua. Sindicato e union apresentam ainda maiores complicações, pois essa palavra em inglês designa, além de 'sindicato', 'união', com toda a diversidade de significados que esta palavra tem, tanto em português como em inglês, ao passo que sindicato em português não carrega nenhuma carga semântica além do seu sentido comum. Em outras palavras, são menores as ressonâncias da palavra sindicato relativamente à inglesa union. Tratando-se de poesia, convém levar em conta o número de sílabas, que do português para o inglês é de $4 / 2,3 / 1$ e $4 / 2$, ou seja, imaginando um improvável verso com essas três palavras, ele teria 12 sílabas em português e apenas cinco em inglês. Aliás, o número de sílabas é um dos principais problemas das traduções do inglês para as línguas latinas, uma vez que uma parte expressiva do léxico dessa língua é constituída de monossílabos, quase inexistentes nas línguas românicas. A tradução do latim clássico para as línguas latinas modernas apresenta problema semelhante, dada a quase inexistência de conjunções e conectivos afins na língua fonte, e que são abundantes nas línguas de chegada. Crescem as dificuldades, se lembramos a presença das declinações indicadoras de caso, inexistentes nessas línguas, e a elisão do verbo esse/sum, tão comum no latim e no grego clássicos quanto rara nessas línguas.

Além disso, como reproduzir na língua de chegada as assonâncias, aliterações e paronomásias, as rimas internas, as onomatopéias, etc. presentes em um poema? Como transportar de uma a outra língua forma e conteúdo, tão unidos na poesia? Pelo menos um deles senão os dois - naufragará.

A tradução da poesia clássica faz crescer exponencialmente os problemas e dificuldades postas para o tradutor, pois milhares de anos nos separam do tempo histórico em que foi escrita. Como recuperar o significado e implicações das palavras tanto tempo depois? Como construir as inferências adequadas a um poema escrito em línguas que há séculos e séculos só existem para os estudiosos? São tarefas impossíveis de serem realizadas. As poesias grega e latina 
prescindiam da rima, sendo o ritmo dado pelos pés e cesuras do verso. É quase impossível transpor esse recurso para nossa língua, uma vez que não somos sequer capazes de saber como era feita a marcação dos ritmos fortes e fracos em latim e grego clássicos.

Esteban Torre ecoa Jakobson: "[...] todos os especialistas estão de acordo em que a adequada tradução de um poema é algo realmente impossível." (TORRE, 1994, p. 159). O poeta norte-americano Robert Frost disse que "poesia é aquilo que se perde na tradução", como cita Paulo Leminski no poema "Limites ao Léu". São afirmações categóricas e difíceis de contornar, mas como resolver o problema que elas apontam? Em nosso mundo existem milhares de línguas. Alguns lingüistas dizem que são mais de seis mil. ${ }^{13}$ Entre os falantes de tantas línguas, apenas alguns poucos falam mais de uma. A solução seria negar a esses monolíngües a leitura da Poesia de outros idiomas? Certamente não. A solução adequada está em o tradutor, humildemente, reconhecer os limites estreitos do ofício a que se propôs e tentar construir, na língua de chegada, paráfrases e metáforas que permitam ao seu leitor aproximar-se do original e vislumbrar a beleza a que não tem integral acesso, mas da qual se torna sabedor através do trabalho do tradutor, esse "recriador intercultural".

Segundo o filósofo espanhol José Ortega y Gasset, a tradução é simplesmente impossível. Esta é a sua miséria. Propor-se a traduzir uma obra literária de uma língua a outra seria, assim, uma espécie de empreendimento utópico. No entanto, conclui o filósofo, tudo “...que o homem faz é utópico" (1964, p. 433) e, portanto, condenado ao fracasso. O fracasso da tradução é um empreendimento que vale a pena ser tocado. A grandeza do ser humano está nisso para o pensador espanhol - tentar mesmo sabendo-se condenado ao fracasso; tentar e tentar.

Ortega e Gasset diz que “...a efetividade do falar não é só dizer, manifestar, mas é, ao mesmo tempo, inexoravelmente, renunciar a dizer, calar, silenciar" (1964, p. 443). "Um ser que não fora capaz de renunciar a dizer muitas coisas, seria incapaz de falar" (1964, 444). Como traduzir para outra língua o não-dito, uma vez que o que se 
cala em uma língua nunca é o mesmo que se cala em outra? Como traduzir se cada língua é uma diferente equação de falas e silêncios? Exatamente isso, para o filósofo, torna magnífica a tarefa do tradutor. Traduzir permitiria, assim, revelar os segredos que os povos e as épocas guardam para si. O empreendimento do humilde trabalhador que é o tradutor tornaria possível uma aproximação maior entre os seres humanos, "uma audaz integração da Humanidade." (ORTEGA y GASSET, 1964, p. 444). Esse, o esplendor da tradução.

Traductio - onis e translatio - onis, palavras latinas apropriadas pelo português e pelo inglês para falar de tradução, são também e não por acaso - as palavras que os gramáticos latinos usavam para dizer metonímia e metáfora, respectivamente. O continente pelo conteúdo (ou a parte pelo todo), e a palavra tomando o sentido da outra palavra; não é exatamente esse o sentido e o conteúdo da tradução?

\section{CONSIDERAÇÕES FINAIS}

Partindo do conto de Jorge Luís Borges, "Pierre Menard, Autor del Quijote", aqui tomado como uma metáfora do trabalho do tradutor, tentamos rastrear - de Cícero, na Roma Clássica, até os nossos dias - a reflexão sobre a tradução e sua importância na nossa cultura.

Este ensaio certamente não oferecerá a seu eventual leitor ou leitora resposta às suas dúvidas e aos seus questionamentos sobre a tradução interlingual. Nem era esse seu objetivo. Tentou-se aqui, antes de tudo, suscitar a discussão sobre o assunto e não elucidálo, o que, aliás, seria impossível tanto pela magnitude do tema quanto pelos parcos recursos do autor. Se, após lê-lo, esse eventual leitor ou leitora tiver mais dúvidas que ao iniciar a leitura, terá este trabalho cumprido seu propósito.

De Cícero e seu De optimo genere oratorum, com sua proposta de tradução "ut orator", chegamos a São Jerônimo, que retorna ao Horácio da "Arte Poética" e, deste, chegamos aos teóricos dos nossos dias, num percurso sumário e inquiridor, tentando compreender a tradução e pensar seus limites e suas possibilidades. 
Na segunda linha desta conclusão, a palavra metáfora, não por acaso, aparece mais uma vez neste texto. Não por acaso, porque falar de tradução é, certamente, falar de metáfora.

\section{NOTAS}

1 "Não queria compor outro Quixote - o que é fácil - apenas o Quixote." As traduções do texto de Jorge Luís Borges são literais e de responsabilidade do autor do artigo.

2 "Sua admirável ambição era produzir umas páginas que coincidissem - palavra por palavra e linha por linha - com as de Miguel de Cervantes."

3 "Meu propósito é meramente assombroso."

4 "Minha empresa não é difícil, essencialmente, me bastaria ser mortal para levála a cabo."

5 "O método inicial que imaginou era relativamente singelo. Conhecer bem o espanhol, recuperar a fé católica, guerrear contra os mouros e contra o turco, esquecer a história da Europa entre os anos de 1602 e 1918, ser Miguel de Cervantes."

${ }^{6}$ Veja nota 13, à frente.

7 As traduções dos trechos de obras citadas em língua estrangeira são de responsabilidade do autor do artigo.

${ }^{8}$ Parece estar aqui a resposta a uma inquietação do poeta argentino Jorge Luis Borges. "Sempre quis saber a origem das traduções literais" (BORGES, 2000, p. 77), diz ele. Ao que parece, está aí, em São Jerônimo, a resposta ao poeta.

9 "Ars poetica" - assim ficou conhecida a epístola dirigida aos Pisões, pai e filhos, também chamada, em latim, "Epistula ad Pisones". Esse texto existe publicado em português, pela Editora Cultrix, de São Paulo, juntamente com a "Poética" de Aristóteles e com o tratado "Do Sublime", de Longino, em tradução direta do grego e do latim, pelo professor Jaime Bruna.

${ }^{10}$ Trata-se dos versos 134 e 135 da "Arte poética" (Epistula ad Pisones). São os seguintes os versos completos:

Nec uerbum uerbo curabis reddere fidus

Interpres, nec desilies imitator in artum. (HORACE, 1950, p. 270) 
${ }^{11}$ Diz Manguel com muita ironia e não menos senso de humor:

Mas a verdade é que (como todo tradutor descobre no começo da primeira página) a fênix imaginada numa língua não passa de uma galinha choca na outra, e que, para investir aquela ave singular da majestade do pássaro nascido das próprias cinzas, uma língua diferente talvez exija a presença de uma criatura diferente, arrancada de bestiários que possuem suas próprias noções de estranheza. (MANGUEL, 2000. p. 134)

${ }^{12}$ Segundo Ortega y Gasset, isso se dá porque o texto técnico está escrito em uma pseudolíngua formada pelos termos técnicos. Ao traduzir, basta que ele seja adaptado a uma espécie de língua que é quase a mesma em que estava escrito originalmente. O filósofo lembra que essa pseudolíngua não é sequer entendida pelas pessoas comuns, que necessitam que tais textos lhes sejam traduzidos. Segundo ele, "Uma língua é um sistema de signos verbais graças ao qual os indivíduos podem entender-se sem prévio acordo.” (ORTEGA y GASSET, 1964, p. 435). A terminologia científca não preenche essa condição, por isso é uma pseudolíngua.

${ }^{13}$ Segundo matéria saída no jornal Folha de S. Paulo, existiam, catalogadas, no mundo, com dados atualizados em nove de dezembro de 2000, 6809 idiomas. Duzentas e trinta e seis dessas línguas são brasileiras, quarenta e uma das quais já extintas. (MACHADO, 2000, p. E1)

\section{REFERÊNCIAS BIBLIOGRÁFICAS}

BORGES, Jorge Luis. Pierre Menard, Autor del Quijote. In: Obra Completa. tomo I. Barcelona: Emecé, 1989.

BORGES, Jorge Luis. Esse oficio do verso. Trad. José Marcos Macedo. São Paulo: Companhia das Letras, 2000.

CICÉRON. De optimo genere oratorum. In: RICHARD, Francis. (trad. et org.). Cicéron, Brutus et la perfection oratoire. Paris: Garnier Frères, 1934.

HORACE. Oeuvres completes: satires, épitres, Art poétique. v 2. Paris: Garnier, 1950 .

JAKOBSON, Roman. Lingüística e Comunicação. Trad. Isidoro Blikstein e José Paulo Paes. São Paulo: Cultrix, 1969.

MACHADO, Cassiamo Elek. O silêncio dos idiomas. Folha de S. Paulo, quintafeira, 21 dez. 2000. p. E1. 
MANGUEL, Alberto. No bosque do espelbo: ensaios sobre as palavras e o mundo. Trad. Pedro Maia Soares. São Paulo: Companhia das Letras, 2000.

ORTEGA Y GASSET, José. Miseria y esplendor de la traducción. In: Obras completas. Tomo V. 6.ed. Madrid: Revista de Occidente, 1964. p. 431-452.

PYM, Anthony. Epistemological Problems in Translation and its Teaching. Teruel: Caminade, 1993.

SAN JERÓNIMO. Ad Pammaquium de optimo genere interpretandi. In: TORRE, Esteban. Teoria de la Traducción Literaria. Madri: Sintesis, 1994. p. 209-211.

TORRE, Esteban. Teoria de la Traducción Literaria. Madrid: Sintesis, 1994. 